fields of Orthopteroid research, the Anti-Locust Research Centre has issued a questionnaire to all persons known to be engaged in such work asking them for information on their research programmes. The data gathered from this survey will be circulated in the form of an indexed list of workers and their current problems, and distributed to all interested institutions and persons. Any workers who wish to be included in the list, or to receive it when published, are asked to write to the Director, AntiIocust Research Centre, 1 Princes Gate, London, S.W.7.

\section{Zoological Nomenclature}

THE International Commission on Zoological Nomenclature gives notice that as from July 25, 1957, it will start voting on the following cases involving the possible use of its plenary powers for the purposes specified. Full deteils were published on January 25 in the Bulletin of Zoological Nomenclature (13, Part 1): (1) bullata Müller (O.F.), 1776 (Akera), validation (Cl. Gastropoda) ; (2) bengalensis Daudin, [1802] (Tupinambis) and salvator Laurenti, 1768 (Stellio), validation (Cl. Reptiliz); (3) Bithys and Chrysophanus Hübner, 1818 (Neotropical Theclids), suppression (Cl. Insecta, Order Lepidoptera); (4) Cephalomutilla André (1908), designation of type species (Cl. Insecta, Order Hymenoptera); (5) A urelia Lamarck, 1816, validation (Cl. Scyphozoa); (6) Indiana Matthew, 1902, designation of type species (Cl. Crustacea, Order Ostracoda). Comments should be sent as soon as possible and in duplicate to Francis Hemming, Secretary to the Commission, 28 Park Village East, Regent's Park, London, N.W.1.

\section{"The X-ray Powder Data File"}

Dr. G. W. Brindley requests the authors of papers describing investigations in which X-ray powder measurements were made, but omitting the actual X-ray data, to submit these data to him as Editor of the Joint Committee on Chemical Analysis by Powder Diffraction Methods, for possible inclusion in the "X-ray Powder Data File" published by the American Society for Testing Materials. The data should include accurate lists of ' $d$ ' values and intensities of reflexions. Other items of information of value for the data file are : $h k l$ indices and lattice parameters if known, radiation used, type of X-ray recording employed, method of estimating intensities (visual, photometric, Geiger-counter), plus any relevant information concerning the nature and preparation of specimens studied. The address of Dr. Brindley is : The Editor, "X-ray Powder Data File", College of Mineral Industries, Pennsylvania State University.

\section{Life Insurance Medical Research Fund of Australia and New Zealand}

The Life Insurance Medical Research Fund of Australia and New Zealand has been established by the Life Offices' Association for Australasia to promote and assist scientific and medical research. For the present it is intended to use the resources of the Fund to stimulate and support research in the field of cardiovascular function and disease.

Grants in aid will be given to non-profit making institutions with basic facilities and qualified personnel for medical research to be used in support of a specific programme of investigation under the direction of a particular investigator. Both fundamental and clinical research projects will be sup- ported. Grants will usually range from $£ 1,000$ to $£ 3,000$ per annum, to cover all the financial requirements of a programme.

Research Fellowships will be open to medical graduates or those with equivalent scientific training for full-time research on fundamental problems broadly related to cardiovascular function and disease or clinical investigations in these fields. Fellowships taken up in Australia and New Zealand will be granted for one year in the first instance, for work in an approved institution, under the supervision of a qualified investigator. Awards will range from $£ 1,800$ to $£ 2,000$ for the term of one year. Travelling Fellowships will be granted for a period of two years abroad, followed by a third year in an approved institution in Australia or New Zealand. Awards will range from $£ 2,000$ to $£ 2,250$ per annum, and in addition approved travelling expenses will be allowed.

Further information and application forms (to be returned before July 1) may be obtained from Dr. J. H. Halliday, Medical Director, Life Insurance Medical Research Fund of Australia and New Zealand, 87 Pitt Street, Sydney, New South Wales.

\section{International Symposium on Curare}

A sxmposrom on the problem of curare and curarizing substances will take place in Brazil during August 5-17, organized by Unesco, the Conselho Nacional de Pesquisas (National Council of Research, Brazil), the Academia Brasilera de Ciencias and the University of Brazil. During August 5-10 meetings will be held at the University of Brezil in Rio de Janeiro on $(a)$ the ethnographic problems concerning South American curares ; (b) the botanical origin of the active principles of curares ; $(c)$ the chemistry of the curarizing alkaloids; $(d)$ synthetic curares; (e) physiology of neuromuscular transmission and mechanism of curarization; $(f)$ pharmacological properties; $(g)$ clinical epplications of curares. During August 11-17 a visit to Manaus (Instituto Nacional de Pesquisas de Amazonia) and to Belem (Instituto Agronomico do Norte) will be arranged. The official languages of the symposium are Portuguese, English, French and Spanish, and the proceedings will be published by Unesco and the Paternò Foundation of the Istituto Superiore di Sanità, Rome. Correspondence should be addressed either to Prof. C. Chagas, Instituto de Biofisica, Universidade do Brasil, 458 Avenida Pasteur, Rio de Janeiro, or to Prof. Daniel Bovet, Istituto Superiore di Sanità, 299 Viale Regina Elena, Rome, or to Prof. P. B. Carneiro, Délégation du Brésil, Unesco, $19 \mathrm{Av}$. Klóber, Paris 16.

\section{Nutrition of Parasites}

THE Institute of Biology is arranging a whole-day symposium on "The Nutrition of Parasites", which will be held in the rooms of the Royal Entomological Society, 41 Queen's Gate, London, S.W.7, on April 12. The morning session will deal with the nutrition of parasitic protozoa and will include papers on amobx, trichomonads, trypanosomes, plasmodia and the ciliates of ruminants. In the afternoon the nutrition of helminths is to be considered : papers will deal with the in vitro and in vivo approaches to helminth nutrition, the feeding habits of trematodes and the nutrition of nematodes. The symposium will be open to all interested persons. Further particulars may be obtained from the General Secretary, Institute of Biology, 41 Queen's Gate, London, S.W.7. 